\title{
Shaping young medicos: IndiaClen's Mandate to promote postgraduate medical research
}

Research is an integral part of postgraduate medical training in India as well as in other countries. During the annual IndiaClen conference in 2013, recommendations for improving postgraduate medical research and publications were formulated after extensive discussions [1]. Medical students, especially during postgraduate studies, must be mentored to be aware of the processes, which go into generation of evidence. This would also make them competent in reviewing evidence and identifying gaps in literature, thus learning to formulate research questions. Simultaneously there is a need for faculty development programs to strengthen areas of research methodology and manuscript writing. Institutional commitment is of paramount importance. After the conduct of research and submitting the theses, postgraduate research goes into the so-called "grey area". The students with their guides must learn to synthesize and organize their work into a manuscript for critical peer review and publication. The students often find this a daunting task, as they have to compete with seasoned researchers and scientific writers. To promote research publications by the postgraduates, Indiaclen has taken the initiative to bring out this supplement. IndiaClen is perhaps the first organization globally which has come out with a supplement only meant only for the postgraduate research work.

In this supplement there are 19 original research works done by the medical postgraduates. They have used diverse study designs ranging from diagnostic test evaluation, qualitative research, surveys, case series, prognostic studies and have worked both in the hospitals and the community. The areas chosen for work are also high health priority areas in India as well as in other middle- income countries, like neonatal and maternal health, community acquired pneumonia in preschool children, autism, and hospital acquired infections and genetics of retinoblastoma. All the essential elements of planning and reporting research have been adhered to. The findings of all the works do contribute to the advancement of science. Yet none of the manuscripts have addressed the translational aspect of their research work adequately. Strong translational aspect has been identified as one of the "best practice" for medical research [2]. Clearly the guides as well as the postgraduates have to be trained for this. Without focus on translation, the possibility of societal benefit from research is throttled in infancy.

Research promotes academic bend of mind. Research in the formative stages of medical graduates and postgraduates leaves a deep impression and molds their future careers. However, the obvious limitations are the issue of generalizability, often lack of clinically meaningful endpoints, which require longer follow-up and picking up modest, but clinically meaningful effects that require larger sample size. The mentors, or the postgraduate teachers, and the institutions can provide financial support to the students [3]. To overcome these limitations, one novel concept is that each student guide develops a comprehensive, phased project and different students can sequentially work on its components. The flip side is that this approach may hamper creativity of the students. One approach may not suit all the institutions or students. There has to be flexibility of mentoring by teachers trained in research methodology to suit each student. The potential of post graduate research must be explored to its fullest by academicians and institutions.

\section{R E F E R E N C E S}

[1]. IndiaClen 2013 Annual Conference Group (ACG). IndiaClen recommendations for improving postgraduate medical research \& publication. Clinical Epidemiology and Global Health, 2013: Volume 1, Issue 2, Pages 54-57.

[2]. European Science Foundation. Present Status and Future Strategy for Medical Research in Europe. Available at http:// www.esf.org/fileadmin/Public_documents/Publications/ EMRC_White_Paper.pdf accessed on 16th Deecember 2015. 
[3]. Pillai RM, Mehendale S, Awasthi S, Varman GR. The significance of research in post-graduate education and ways to facilitate. Clinical Epidemiology and Global Health. 2015;3(2):58-62.

Shally Awasthi

Department of Pediatrics, King George's Medical University,
E-mail address: shally07@gmail.com http://dx.doi.org/10.1016/j.cegh.2015.11.009 2213-3984/

(C) 2015 INDIACLEN. Published by Elsevier, a division of Reed Elsevier India, Pvt. Ltd. All rights reserved.

Lucknow 